\title{
La indefensión no es sólo una cuestión de prestación. La producción de datos y el sistema de transporte público metropolitano de pasajeros
}

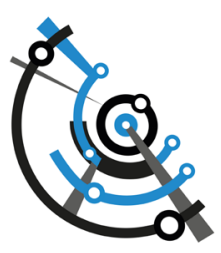

\footnotetext{
(4) Candela Hernández

Instituto de Investigaciones Gino Germani, Facultad de Ciencias Sociales, Universidad de Buenos Aires / Consejo Nacional de Investigaciones Científicas y Técnicas, Argentina. https://orcid.org/oooo-ooo2-3528-9479
}

Recibido: 10 de junio de 2019.Aceptado: 10 de octubre de 2019.

\begin{abstract}
Resumen
La red de transporte público colectivo de pasajeros de la Región Metropolitana de Buenos Aires (RMBA), ofrece cotidianamente a sus usuarios condiciones de prestación que se traducen en una experiencia de viaje poco satisfactoria. Frente a esta situación quienes utilizan el servicio no sólo no saben cuáles son las vías existentes para efectuar posibles quejas sino que, además, desconfían de la capacidad institucional para resolver sus problemas. Esta situación pone de relieve una dimensión central involucrada en la relación entre prestadores, entes de control y usuarios, aquella vinculada a la producción, circulación y uso de la información emergente en el sistema. Este artículo se preocupa por realizar una reflexión metodológica acerca de los reclamos de los usuarios recibidos por los entes de control que involucre la caracterización de los canales institucionales existentes, las representaciones que tienen al respecto quienes efectúan la quejas y el tratamiento dado a los reclamos por las instituciones correspondientes. Hipotetizamos que en la actualidad la capacidad que tienen los entes reguladores para dar tratamiento y utilizar la información relevada es limitada, fragmentada y poco sistemática. Esta condición refuerza el posicionamiento desventajoso de los usuarios por las debilidades que las herramientas institucionales tienen para aproximarse a la medición de las representaciones que hacen quienes hacen uso de los servicios dejándolos en una situación de indefensión.
\end{abstract}




\title{
Defenselessness it's not just a matter of provision of services. Data production and metropolitan public transport network for passengers
}

\begin{abstract}
Metropolitan Area's (RMBA for its Spanish acronym) collective public, offers to it's users daily provision conditions that result in an unsatisfactory travel experience. Those who use the service not only don't know which the existing ways are to make possible complaints, but also distrust the ability to solve their problems. This situation highlights a central dimension involved in the relationship between providers, control entities and users and is linked to the production, circulation and use of the information emerging in the system. This article aims to put into a methodological consideration the existing institutional channels, the representations that have in this regard those who make the complaints and the treatment given to the claims by the corresponding institutions. At present, we hypothesize that the ability of regulatory bodies to produce, process and use the information collected is limited, fragmented and unsystematic. This condition reinforces the disadvantageous positioning of the users due to the weaknesses that the institutional tools have to approach the measurement of the representations of those who make use of the services.
\end{abstract}

Keywords: Collective public transport. Metropolitan Area. Users. Claims. Control entities

Palavras chave: Transporte público coletivo. Região Metropolitana. Usuários. Reclamações. Entidades de controle

\section{Introducción}

El sistema de transporte público colectivo de pasajeros de la Región Metropolitana de Buenos Aires (RMBA), ofrece cotidianamente a sus usuarios condiciones de prestación que complejizan la movilidad urbana diaria y repercuten en una experiencia de viaje poco satisfactoria. Especialmente esta situación ocurre en los modos guiados, (ferrocarriles de superficie y subterráneos) y está acentuada en algunas de las líneas en servicio, donde la disconformidad con la prestación alcanza mayores niveles.

Frente a esta situación quienes utilizan el transporte público, no saben cuáles son los procedimientos institucionales formales de los que disponen para efectuar posibles quejas. Además, quienes los conocen desconfían de la posibilidad de que, a través de éstos, afectivamente sus demandas contribuyan a motorizar acciones de los actores correspondientes para resolver los problemas a lo que se enfrentan día a día. Bajo estas condiciones por su desconocimiento y desconfianza, los usuarios ven vulneradas las posibilidades de ejercer su derecho a quejarse quedando en una situación de indefensión, al verse obturada posibilidad de involucrarse con los servicios más allá de su estricto consumo (Castro, 2006).

Esta situación pone de relieve una dimensión central involucrada en la relación entre prestadores, organismos de control y usuarios; aquella vinculada a la producción, circulación y uso de la información emergente en el sistema.

Desde el lado de los receptores de las demandas, el desincentivo al reclamo produce que los caudales de información generados a través de esas vías sean marginales, limitando las posibilidades de conocer representativamente las problemáticas percibidas por los usuarios y cómo éstas afectan sus prácticas de viaje. Este nudo pone de relieve otro elemento más, vinculado a las formas de procesar los reclamos concretados que, aunque marginales, su tratamiento está previsto en los diseños institucionales 
y su procesamiento efectivo, guarda como orientación construir observables de las problemáticas que afectan el servicio e intervenir sobre los responsables de su prestación. Sin embargo, no necesariamente, las formas de tratamiento y producción de la información refuerzan dicha direccionalidad. En adición, estas distancias propician un desajuste entre lo experimentado por quienes utilizan los servicios y la abstracción que producen las instituciones al generar intervenciones que, no necesariamente, guardan correspondencia con lo que sucede, en este caso, con el carácter que cobra la movilidad metropolitana, produciéndose dislocaciones entre los modos de gestión y las dinámicas efectivas (Jirón et al., 2019).

El eje problemático instalado permite focalizarse sobre distintos interrogantes que podrían ser diferencialmente tratados según el o los actores y el conjunto de relaciones que se tomen como punto referencia del análisis. El objetivo que nos guía está orientado a realizar una reflexión metodológica acerca de los reclamos de los usuarios recibidos por los entes de control que involucre la caracterización de los canales institucionales existentes, las representaciones que tienen quienes efectúan las quejas a través de esta instancia y los modos de tramitar la información recabada por los entes de control. Hipotetizamos que la capacidad que tienen los entes reguladores para producir, dar tratamiento y utilizar la información relevada es limitada, fragmentada y de bajos niveles de sistematicidad. Esta condición abona a la producción de sesgos al despliegue y adecuación de las políticas, obtura la utilización de las estadísticas oficiales para el estudio de esta dimensión y refuerza el posicionamiento desventajoso de los usuarios por las debilidades que las herramientas institucionales presentan para aproximarse a la medición de las principales problemáticas que desde su perspectiva los afectan. Finalmente, procuramos realizar aportes propositivos orientados a mitigar los sesgos existentes que permita hacer uso de la información disponible.

Para desarrollar esta propuesta se articularon metodologías cuantitativas y cualitativas con base a fuentes de información primarias y secundarias. Recurrimos a múltiples relevamientos por encuestas realizados en los años 2007, 2010, 2015 y 2016 en el marco del Taller de Investigaciones sobre Cambio Social (TCS) de la carrera de Sociología de la Universidad de Buenos Aires. Estos fueron aplicados a usuarios de los servicios de transporte ferroviario en las estaciones terminales en los horarios de mayor flujo de circulación de pasajeros en las líneas Roca, Sarmiento y San Martín. Cada uno de los relevamientos cuenta con aproximadamente 400 casos.

Complementariamente en el marco de la tesis de doctorado "Las vías del poder social. Límites y potencialidades a la capacidad asociativa de los usuarios/pasajeros del sistema metropolitano de transporte público colectivo (2002-2017) de propia autoría, fue realizado un relevamiento por encuesta no representativo a usuarios de los servicios de autotransporte y subterráneos. El mismo consta de 400 casos y fue realizado en los horarios de mayor flujo de pasajeros en las líneas D y E (subterráneos) y aplicado en 42 líneas de autotransporte de jurisdicción nacional. El criterio de selección fue según recibieran mayor o menor cantidad de reclamos. A través de estos relevamientos pudieron reconocerse tendencias similares a las relevadas para el caso de los ferrocarriles se superficie. Complementariamente fueron realizadas entrevistas a personal técnico de los organismos de control y grupos focales con pasajeros de los servicios.

También fueron consultados, documentos, informes, normativa específica, y procesadas las bases de datos de reclamos de usuarios para cada modo de transporte provistas por la Comisión Nacional de Regulación del Transporte (CNRT) y por el Gobierno de la Ciudad de Buenos Aires. Esta acción no sólo permitió obtener el dato de cómo este indicador se comporta, sino también, identificar algunas de sus debilidades. Todas estas actividades se inscriben en una investigación más amplia inscripta en el marco de los proyectos UBACyT Transporte Público y Conflicto Social" y el Proyecto de Desarrollo 
Tecnológico y Social (PDTS): "Cuidado y valorización de lo público en el sistema ferroviario metropolitano. Percepciones y prácticas de los usuarios, ambos con sede en el Instituto de Investigaciones Gino Germani.

Temáticamente el artículo está organizado en cuatro apartados. En el primero se describen los mecanismos de reclamo disponibles en los distintos modos de transporte para recibir y viabilizar las quejas de los usuarios vinculadas a problemas con los servicios. En el segundo, se expone acerca del grado de conocimiento y el tipo de valoración que tienen los usuarios respecto de los canales institucionales de reclamo. En el tercero se realiza un análisis de los datos disponibles y las formas de darle tratamiento de acuerdo con las características que presentan. Por último, se instalan algunas reflexiones finales acerca de la problemática abordada.

\section{Vías existentes para procesar la disconformidad}

Diversas acepciones del verbo reclamar aparecen en la definición de diccionario. Una de ellas se destaca por ser la que mejor se adecúa al campo temático sobre el que se está problematizando. Ésta refiere a la acción de "pedir o exigir con derecho o instancia de algo" (RAE, 2019). Dos de los elementos que componen esta definición, resultan significativos: acción y derecho. La primera porque pone de relieve el carácter relacional que interviene entre el reclamante (quien pide o exige) y el reclamado (a quien se le pide o se le exige). La segunda porque el ejercicio del reclamo está fundado sobre la base de un conjunto de principios normativos que ordenan y enmarcan la relación, condicionan expectativas y establecen pautas de reciprocidad mutua no necesariamente equivalentes. El quiebre entre lo esperado bajo los parámetros socialmente consensuados y lo efectivamente recibido, produce una dislocación generadora de disconformidad que deriva de la vulneración de los intereses involucrados en esa relación. Igualmente, la traducción de esta condición al campo de la acción no es mecánica ni necesaria, al operar otros condicionantes en este tránsito (Hernandez, 2019).

En el terreno de los servicios públicos, es el Estado quien debe cautelar, garantizar y proteger el acceso de los miembros de la sociedad a la prestación de los servicios en condición de obligatoriedad, continuidad, regularidad, universalidad y uniformidad. Es decir, el Estado está obligado a organizar técnica, jurídica y económicamente a los servicios a los fines de asegúrale a la comunidad, que éstos sean brindados bajo determinados estándares de calidad, de forma ininterrumpida, a la mayor cantidad de personas bajo un trato uniforme (Olivieri, 1996; González Moras, 2004).

Los usuarios tienen el derecho de reclamarle a los oferentes y al Estado, cuando alguno de los acuerdos que rigen las formas en que se entabla la relación que existe entre prestación y consumo, no sea la adecuada por no cumplir los estándares con los que debiera brindarse y/o en términos relativos, satisfaga la expectativa de quienes hacen uso de los servicios. Éstos quedan en relación con el Estado con base a las potestades que le concede el derecho al consumo, para interpelarlo en su actuación frente a las necesidades materiales y colectivas que se les presenten, al ser este tipo de servicios básicos para el desenvolvimiento de la vida en sociedad, propendiendo al bienestar general (González Moras, 2017).

Las condiciones en que estos se brindan son establecidas por aquellos que están involucrados en la producción del servicio: empresas y Estado. Relación bajo la cual se fijan los parámetros de prestación e instala un esquema con base a derechos y obligaciones del uno para con el otro y de ambos para con los usuarios (Ozslak, Felder y Forcinito, 2000; Oszlak, 2004): cuáles serán los atributos que tendrá el ordenamiento institucional 
en la definición de determinados aspectos de la prestación, las reglas del juego y en qué medida se dispone de la capacidad y la legitimidad para ejercer y ver reconocida su función (Oszlak y Felder, 1997).

En este marco la incorporación de los consumidores a dicha relación, también les confiere un conjunto de derechos y obligaciones a partir de las que deben regular su comportamiento y que ordena los horizontes de interacción. De ambas vías deriva la definición sobre lo que puede y no puede exigirse. Los diseños institucionales que operan sobre estas relaciones delinean las formas de canalización de las demandas y estipulan cuál será el posterior tratamiento por dárseles. Desde la posición del usuario, su derecho a la práctica institucional del reclamo supone como prerrequisito que pueda identificar la vulneración de algunas de las normativas vigentes, cuenten con una predisposición al ejercicio de la queja, sepan ante quien pueden realizar sus denuncias, a través de qué medios hacerlo y confíen en que el reclamo va a tener algún tipo de incidencia en promover la resolución de aquello que genera su disconformidad (Hernández y Rebón, 2017).

En sintonía con cambios en las tendencias globales en la materia que nos concierne, la potestad de reclamo de los usuarios fue puesta de relevancia (Casaburi, Riggirozzi y Tuozz, 2000; Rabotnikof, 2001). En Argentina y para el caso del transporte de la RMBA, la potestad de reclamo de los usuarios resultó ponderada en contexto de los cambios estructurales producidos en la relación entre el Estado, las empresas y los usuarios, por el traspaso de la explotación de los servicios a oferentes privados, ocurrido en contexto de las reformas estructurales implementadas durante los años noventa (Bresser Pereira, 1998; Oszlak, 2004; García, 2008). En este marco la sanción de la Ley de Defensa del Consumidor 24.240 en el año 1993 y la incorporación de los derechos de los consumidores y usuarios al texto constitucional del año 1994, actuaron como telón de fondo, ordenando la nueva trama de relaciones y estableciendo como obligación del Gobierno Nacional velar por sus intereses (López y Felder, 1997; Botto, 2007; García, 2008).

En sintonía con el cambio de rol del Estado de prestador directo a regulador de los servicios, para el caso particular del transporte público metropolitano, las concesiones de los modos guiados al sector privado y las modificaciones del marco regulatorio del servicio de autotransporte de pasajeros (Decreto 656/94), dieron contenido específico a la aplicación del nuevo esquema.

Esta innovación en materia de diseño institucional propició el avance de la normativización de la relación de los prestadores y usuarios en lo relativo a los derechos y las obligaciones de ambas partes. Las empresas -según lo establecido en los contratos de concesión de los servicios ferroviarios de superficie y subterráneos y addendas, debían atender los reclamos de los usuarios vía libro de quejas o disponer con dicho fin, de líneas telefónicas. La Autoridad de Aplicación quedaba como responsable de tramitar y resolver las quejas del público, relativas a los servicios ferroviarios concedidos. Para el autotransporte colectivo de pasajeros, este proceso se enmarcó en las incidencias regulatorias sobre el sector, estableciéndose y reglamentándose mecanismos para la recepción de los reclamos de los usuarios.

El Estado en su función de regulador y fiscalizador, implementó mecanismos para garantizar el control de la operación del sistema de transporte. En este marco fueron creadas la Comisión Nacional de Transporte Automotor (CONTA) (Decreto 104/1993) y la Comisión Nacional de Transporte Ferroviario (Decreto 1836/1993), luego unificadas en el año 1996 en la Comisión Nacional de Regulación del Transporte (CNRT) (Decreto 660/96). Más allá de los reordenamientos de la estructura institucional, al interior de los organismos se crearon gerencias de atención al usuario, entre cuyos objetivos, estuvo y está la comunicación con la comunidad vía: la atención, resolución de reclamos y recepción de sugerencias. 
Posicionándonos desde la óptica del usuario para que sus reclamos puedan ser considerados, deben presentarse de manera individual, consignando para su correcto procesamiento campos específicos -para el caso de los modos guiados: línea, ramal y coche. En el caso del autotransporte colectivo de pasajeros línea, dominio e interno. Para todas las denuncias deben consignarse fecha, hora, lugar y breve descripción del suceso. Como opcional, los datos personales de contacto y elementos probatorios. Las quejas ingresadas solo son computadas si refieren a la violación de los derechos del usuario o al incumplimiento de las normativas vigentes del sector, que se suponen conocidas por quienes hacen uso del servicio. En caso de no guardar correspondencia con ninguna de éstas, la misma no se efectiviza.

Existen diferentes mecanismos institucionales formales a través de las cuales los usuarios de los servicios de transporte de la RMBA pueden efectuar los reclamos relativos a las condiciones de prestación. En términos generales pueden destacarse los directos a través de las empresas prestatarias o los indirectos, vía el ente regulador. Con los años, el avance tecnológico, la generalización del uso de dispositivos informáticos y de telefonía celular y los cambios organizativos que sufrieron algunos de los modos, nutrieron las posibilidades disponibles para realizarlos.

\section{Autotransporte de pasajeros}

En el año 1993 con el Decreto 2044/1993 se reglamentó la estructura organizativa de la Comisión Nacional del Transporte Automotor (CONTA), donde se institucionalizó la Gerencia de Atención al Usuario y los Centros de Atención al Usuario (CAU), dependientes de ésta última. Según se indica en letra de la norma el objetivo de la Gerencia y los mecanismos que implementase, tenían que estar dirigidos a "defender los intereses de los usuarios". Sus competencias consistieron en brindar información sobre los aspectos generales del sistema y su prestación; poner en conocimiento los canales de reclamo disponibles para que puedan ejercitar su derecho a la queja; atender y dar tratamiento a esos reclamos y sistematizar la información entrante para tener una intervención integral sobre dicho ámbito.

En el año 1996 por Resolución 405/1996 del mismo organismo, se aprobó el "Reglamento del Usuario del Transporte Automotor de Pasajeros y Cargas de Jurisdicción Nacional", agrupamiento que contempla la oferta de autotransporte de pasajeros que tiene prestación dentro de la Ciudad de Buenos Aires o entre ésta y los partidos que conforman la RMBA (AGN, 2009). En dicho documento fueron señaladas que las particularidades de los reclamos de estos servicios requerían para su adecuado tratamiento de una reglamentación específica. Los Centros de Atención al Usuario quedaron como la vía institucional dedicada a la recepción de los reclamos, las inquietudes y las sugerencias de los usuarios y a bridarles información sobre los aspectos relacionados con el transporte automotor de jurisdicción nacional. El reglamento tuvo como finalidad mediar en la relación entre los prestadores de los servicios y sus destinatarios, regulando las vías de canalización de las quejas. En adición, tanto las empresas operadoras como el ente regulador, debían disponer de procedimientos para recibir y dar tratamiento a los reclamos. Con dicha finalidad las empresas quedaron en la obligación de ofrecer medios gratuitos de contacto y el ente disponer de los modos presencial, telefónico (por cobro revertido) o apartado postal sin costo de servicio.

En el año 1998 -ya creada la CNRT- la Resolución 405/1996 fue derogada y reemplazada por la Resolución 979/1998 que continua vigente y rige sobre las modalidades de reclamo actuales. Se conformó la ahora llamada Gerencia de Calidad y Prestación de los Servicios de la cual pasaron a depender los Centros de Atención al Usuario del Transporte Automotor. La principal modificación que se introdujo con el cambio de 
normativa fue que la CNRT en tanto unidad de recepción de los reclamos, pasara a segundo término, es decir, se estableció que primero se le reclame a la empresa y en caso de no tener respuesta a la Comisión.

Según la resolución dicho cambio se sustentó sobre la experiencia en materia de reclamo recogida hasta el momento, a partir de la cual se diagnosticó una débil relación entre las empresas prestatarias y los usuarios, visualizándose como un limitante a la percepción empresaria respecto de su gestión. A la par se sostuvo que este cambio permitiría agilizar el tratamiento dado a las denuncias, al reducir los intermediarios y que la empresa pudiera darles curso directo.

Las prestadoras quedaron como responsables principales de recibir y procesar las quejas de los usuarios, debiendo disponer de una línea gratuita de atención telefónica obligatoria, difundida por cartelería oficial al interior y exterior de las unidades de servicio.

Recibida la queja por parte de la operadora, las empresas cuentan con treinta días corridos para dar respuesta al reclamo. En caso de que así no lo hicieran o la respuesta no fuera satisfactoria o se negase a recibir el reclamo, es entonces cuando ésta puede reiterarse ante el órgano regulador. Para los casos en que la denuncia esté vinculada a un presunto acto de violencia física ejercido por parte de un conductor, la empresa deberá elevar un informe de lo sucedido con un plazo de 72 horas corridas al ente regulador.

En caso de que la denuncia fuera radicada en el organismo directamente salteando a la empresa, éste debe actúan de manera inmediata si la queja recibida refiere a un evento que atentó o -al momento de estar siendo denunciada- atenta la seguridad de los usuarios. Por ejemplo, una situación de acoso o un desperfecto técnico severo que pueda ser percibido por el reclamante. Caso contrario, el organismo da intervención a un supervisor cuando se produjese una cantidad significativa de reclamos que refieran a una misma problemática. El agente enviado debe constatar lo denunciado y en caso de corroborarse, el organismo inicia sanciones a la empresa en infracción. En una entrevista era señalado lo siguiente:

Ciertos tipos de quejas requieren la producción de una "masa crítica". Esto es, una cantidad importante de quejas que refieran al mismo tema. En particular, los reclamos referidos a la forma de explotación de los servicios, cancelaciones y demoras se encuentran dentro de este tipo. Cuando la masa crítica se constituye, orienta la acción del organismo hacia la realización de inspecciones específicas (Informante clave 1 CNRT, 2009).

En este caso lo formal no explicó lo sucedido en términos procedimentales. De acuerdo con el testimonio de otro informante clave -para todos los modos- el organismo no se adecuó estrictamente a la normativa, recibiendo reclamos aun cuando no fueran realizados en primera instancia ante las empresas y derivándolos a las mismas (Informante clave 2 CNRT, 2018).

Según su testimonio, la implementación efectiva de lo establecido en la Resolución 979/98 comenzó a suceder a partir de abril/mayo del año 2018. Para el caso del autotransporte de pasajeros implicó un trastocamiento de la cultura de reclamo y de las capacidades del organismo para actuar en dicho campo. De acuerdo con su argumentación, los usuarios de este modo tenían incorporado efectuar sus quejas mayoritariamente ante el ente regulador quien las recibía y canalizaba. En sus palabras:

En trenes hay una predisposición mayor a quejarse con la prestadora. En colectivos, no. Es con la CNRT. Esto hizo que los o80o- de las empresas, nunca fueran un mecanismo muy difundido en su uso ni controlado en su efectivo funcionamiento 
Si bien no disponemos de datos para el caso del autotransporte de pasajeros que puedan sostener efectivamente esta hipótesis, consideramos que un indicador para dar asidero a lo dicho se instala en los niveles de desconocimiento y dificultades a la accesibilidad que los usuarios manifiestan tienen para ponerse en contacto con las empresas (Relevamiento Hernández, 2018).

En este cambio, el usuario queda en relación obligada con las prestatarias quienes deben adecuarse a la normativa y disponer de los canales de reclamo que le son obligatorios. Esta aplicación generó para el servicio de autotransporte que muchas empresas tercerizaran las vías de contacto con el usuario en consultoras dedicadas a recaban las denuncias. A septiembre de 2018 eran dos las empresas que daban cobertura a la recepción de reclamos. Por entonces este servicio estaba disponible para 108 de las 137 líneas en actividad bajo jurisdicción nacional. Esta situación deja a los usuarios en una condición de mayor indefensión frente a las prestadoras privadas ocupadas íntegramente del mercado de viajes de este servicio: "Con el cambio de instancia se le acota al organismo la relación con el pasajero" (Informante clave 2 CNRT, 13 de septiembre de 2018).

$\mathrm{Al}$ momento del trabajo de campo el ente se encontraba en proceso de adaptación a nivel institucional. Mismo comportamiento era visualizado en los reclamantes quienes debían redireccionar su práctica de reclamo para viabilizarlos a través del actor correspondiente. En palabras de uno de los informantes: "Hoy en día el servicio de las empresas no es bueno. Está en proceso. Recién hoy en día se le da la obligación con el usuario y no todas las empresas contemplan la diversidad del usuario" (Informante clave 2, 13 de septiembre de 2018). Posiblemente los cambios producidos en la efectiva aplicación de la normativa donde la CNRT pasó a organismo de segundo término, generen variaciones respecto al uso de los canales.

En la actualidad las modalidades de reclamo vigentes son a través de las líneas telefónicas de las empresas, informadas en las señaléticas reglamentarias, o en segundo orden de modo presencial en la sede central de la CNRT o en sus respectivas delegaciones regionales (en caso de servicios interurbanos). Las quejas ante este último organismo, también se pueden realizar completando un formulario web (http://denuncias.cnrt. gob.ar), enviando un correo electrónico (atencionalciudadano@cnrt.gob.ar), una carta o llamando a una línea telefónica gratuita (0800-333-0300). Puede contactarse al ente siempre que el reclamo haya sido primero realizado ante la empresa y no se haya obtenido respuesta luego de 30 días de efectuado. En la actualidad es requisito obligatorio que esto pueda ser comprobado a través del número asignado por la empresa al trámite de queja. En su conjunto todos estos mecanismos conforman lo que el Ente llama sistema de denuncia.

\section{Ferrocarriles de superficie}

En los acuerdos de concesión de los distintos grupos de servicios, figura en sus artículos la obligatoriedad de disponer del libro de quejas por parte de las concesionarias para recibir los reclamos de los usuarios en todas las boleterías y paradas de la red habilitadas a dicho fin. También los concesionarios metropolitanos crearon en las estaciones cabeceras de sus líneas, Centros de Atención al Pasajero y habilitaron canales telefónicos de contacto.

Dos años después de la conformación de la CNRT, en 1998 por Resolución 823 se jerarquizó la línea telefónica de las operadoras como modo de atención y se equiparó su validez y tratamiento al de las quejas ingresadas por los libros. Para el caso de los 
ferrocarriles, la habilitación de estos mecanismos respondió a los objetivos del ente de fiscalizar y controlar la ejecución de las concesiones, de acuerdo con lo establecido en los contratos de explotación privada de los servicios, relativos a la cantidad y calidad de la oferta, tomando como uno de sus indicadores las quejas y reclamos de los usuarios. Mecanismo que permitiera en dicha coyuntura de cambios materializar la función reguladora del Estado (Oszlak y Felder, 1997).

En la actualidad equiparando la normativa vigente para el autotransporte de pasajeros y la transición en la que se encuentra el organismo, para el caso ferroviario, la Comisión Nacional de Regulación del Transporte, también cumple funciones en segundo término luego de efectuados los reclamos antes las prestadoras y transcurridos treinta días desde su ingreso.

Los canales de reclamos varían según cual sea su destinatario, conforme el modelo de explotación bajo el que estén en funcionamiento las líneas. Para el caso de los servicios que aún se mantienen bajo el régimen de concesión (Urquiza y Belgrano Norte) los reclamos pueden realizarse mediante el libro de quejas en las boleterías o Centros de Atención al Usuario u Oficinas de Atención al Pasajero o por línea directa y gratuita al 0800-555-1616 o 0800-777-FERR (3377), respectivamente.

Para el caso de las líneas bajo gestión estatal (Belgrano Sur, Sarmiento, Mitre, Roca y San Martín), las quejas deben realizarse ante la Operadora Ferroviaria Sociedad del Estado (SOF.SE). Los reclamos pueden presentarse por vía telefónica a través del 0800222-(TREN), por correo electrónico, formulario web (https://reclamoscap.sofse.gob. ar/) o también personalmente en el libro de quejas de las estaciones y en los centros de Atención al Pasajero (CAP), ubicados en las terminales.

Desde que la Operadora Ferroviaria Sociedad del Estado (SOF.S.E.) asumió cinco de los siete servicios de la red de ferrocarriles de superficie, viene realizado distintas innovaciones en materia de vías de contacto con los usuarios. En la actualidad, está trabajando para habilitar nuevos canales para a recepcionar reclamos. Desde el último semestre de 2017, se impulsó la Central de Atención Telefónica que permitió a la operadora unificar los registros de reclamo de las líneas bajo su operación.

Antes de septiembre del año pasado estaba disgregada la atención telefónica en todas las líneas. No teníamos ningún registro de cuántas llamadas entraban, por qué nos llamaba la gente y tampoco sabíamos cuántas llamadas perdíamos y a cuántos estábamos dejando de atender (Informante clave SOFSE, 15 de agostos de 2018).

Si bien esta vía de contacto ya existía, en su uso principal respondía a la recepción de consultas sobre los servicios. Su centralización operativa apuntó a reforzar este canal como medio de recepción de reclamo y agilizar el tratamiento dado a las quejas y su derivación a las áreas con competencia. La difusión de esta vía la realizan ponderándola en la información brindada al usuario por sobre los otros canales existentes. Actualmente la empresa está desarrollando un sistema de atención de reclamos vía la aplicación móvil o APP "Trenes Argentinos". A través de esta se pusieron a disposición canales de contacto web con atención en simultáneo por parte de agentes virtuales a los que puede contactarse por ventanas de chat (Informante clave SOFSE, 15 de agosto de 2018).

Acorde a los datos proporcionados por la CNRT, para el caso de los ferrocarriles de superficie, la mayor cantidad de los reclamos ingresan por vía de los operadores del servicio, seguidos minoritariamente por aquellos que eran recibidos a través del propio organismo (Base de datos de reclamos CNRT, 2002-2016). La forma de reclamo más frecuentemente utilizada por los usuarios para el caso de la Operadora Ferroviaria y las concesionarias, es el libro de quejas en las estaciones. En cambio, los recibidos por 
la CNRT provienen mayoritariamente de la línea telefónica y, a partir del 2013, año de su implementación efectiva, de la página web del organismo (Informante clave 3 CNRT, 2015). En particular el libro de quejas es una vía relevante en la tramitación de los reclamos. Este es referido desde el año 1936 en el Reglamento General de Ferrocarriles aprobado por Decreto 90.325 donde se indica que los mismos deben estar a disposición de los usuarios en todas las estaciones y paradas habilitadas. De hecho, en una entrevista realizada en la CNRT, quien brindaba testimonio se referían a este modo de reclamo de la siguiente manera: "El libro es histórico, es el Padrenuestro (...) los usuarios tienen mucha cultura del libro" (Informante clave 3 CNRT, 2015).

El conjunto de los reclamos ingresados por las operadoras es centralizado en los CAP, quienes deben encargarse de cargar, derivar por área específica de competencia cada una de las denuncias y dar una respuesta. Si bien los operadores- ya sean privados o estatales- tienen su propio protocolo para este procedimiento, deben llevar un registro del tipo de quejas efectuadas y del tratamiento brindado. Específicamente, los reclamos ingresados a través del libro de quejas deben ser elevados a la CNRT, donde es evaluada la correspondencia entre el tipo de problemáticas asentadas y las respuestas brindadas a los mismos. Las quejas que ingresan a la CNRT son tramitadas por la Gerencia de Calidad y Prestación del Servicio que, según sus competencias, da curso directo a la efectivización de los reclamos o los deriva a las gerencias correspondientes, según sea adecuado para su tratamiento (Entrevista informante clave 3 CNRT, 2015).

Para el caso de los ferrocarriles de superficie significó la implementación de un sistema de denuncias diferente según la gestión bajo la que se encuentren las líneas. Las concesionadas continuaron con el esquema implementado al momento del traspaso de su explotación. Por su parte las que ingresaron a la órbita de la gestión estatal, asistieron a la jerarquización y modernización de los mecanismos para contactar con los usuarios, observable en las distintas acciones mencionadas con anterioridad. Una informante clave de la SOFSE relataba que la efectiva implementación de la normativa fue demandada por el Área de Atención al Pasajero de la empresa estatal, por considerar que el ingreso de reclamos a la CNRT -que posteriormente les son derivados para su tratamiento-, ralentizaba el procesamiento y resolución de las quejas. Dicho pedido se extendió a todos los modos bajo jurisdicción nacional.

\section{Ferrocarriles subterráneos}

Los ferrocarriles subterráneos y el premetro o tranvía (término al que puede asimilarse este modo en otras locaciones), comparten una trayectoria común con los otros servicios por haber estado hasta fines del año 2011, bajo jurisdicción nacional y por tanto bajo regulación de la CNRT. Esta condición cambió con su traspaso a la órbita de la Ciudad Autónoma de Buenos Aires (Ley 26.740/2012). Hasta tanto, los mecanismos de reclamo para el caso del subterráneo de Buenos Aires, tuvieron un formato similar al de los ferrocarriles metropolitanos de superficie bajo el esquema de explotación privada de los servicios.

De acuerdo con el contrato de concesión, la empresa Metrovías S.A, estaba obligada a atender los reclamos del público. Para ello debía disponer del libro de quejas en todas las estaciones y paradas habilitadas. Por entonces, la Autoridad de aplicación era la Municipalidad de Buenos Aires que tenía como función tramitar y resolver las quejas de los usuarios (Contrato de concesión grupo de servicios 3 y addendas, 1999). Tres años después de la concesión ocurrida en 1994 y creada la CNRT, la Gerencia de Calidad y Prestación de los Servicios, tuvo jurisdicción sobre el ferrocarril subterráneo y pasó a ocupar un papel activo en la recepción de las quejas. El ente se encargó entonces de tramitarlas a través de los canales que disponía -iguales para todos los servicios- y del control y fiscalización de las acciones que sobre dicha materia tuviera Metrovías S.A. 
Por entonces quedaban bajo su jurisdicción el total de los modos que componen el sistema de transporte público colectivo metropolitano.

En el año 2013 Subterráneos de Buenos Aires Sociedad del Estado (SBASE) y Metrovías S.A., suscribieron el Acuerdo de Operación y Mantenimiento (AOM). En el cuarto apartado del AOM se establecieron los procedimientos para atender los reclamos o quejas de los usuarios que pasaron bajo la jurisdicción de SBASE y la Ciudad de Buenos Aires. La empresa quedó obligada a continuar atendiendo las demandas a través del libro de quejas en las boleterías habilitadas y Centros de Atención al Usuario. Respecto a la recepción y tratamiento de las mismas, la innovación que este acuerdo trajo fue su incorporación al Sistema Único de Atención Ciudadana (SUACI) del Gobierno de la Ciudad de Buenos Aires. Este permite iniciar múltiples y disimiles trámites y solicitar turnos en organismos públicos y realizar reclamos o sugerencias teniendo un seguimiento de las distintas acciones. La novedad del sistema es que cualquiera fuera la vía de contacto utilizada, se centraliza toda la información en una sola base de datos.

Bajo este sistema, los reclamos ingresados por libro de quejas son incorporados por SBASE a este registro único, donde converge con los ingresados por las otras vías disponibles que son: formulario web en la página de la Ciudad (buenosaires.gob.ar); los Centros de Gestión y Participación Comunal (CGPC), Centro de Atención Telefónico de la Ciudad (147); las aplicaciones operativas por telefonía celular como BASubte y BA147 y terminales de auto-consulta.

$\mathrm{Al}$ igual que ocurre en los otros modos, se solicita al reclamante datos de identificación personal. En el caso del subte no puede efectivizarse el reclamo sin información respecto a la identidad del reclamante (para canales virtuales ingresar vía perfil de Facebook o Google, resume este paso que constituye un campo obligatorio donde debe consignarse nombre, apellido y DNI). Luego se solicitan los datos del hecho discriminados según: fecha, línea, estación, destino, coche. Respecto a los motivos de reclamos según se indica en letra del Acuerdo Operativo, se sintetizaron las opciones posibles.

Según la CNRT hasta donde se recopiló información de los reclamos (año 2011), al igual que ocurre con los ferrocarriles de superficie, una significativa porción ingresó a través de la concesionaria vía el libro de quejas y en menor medida lo hizo por la línea telefónica del Ente (Base de reclamos CNRT, 2002-2011).

El registro SUACI recién en 2017 incorporó a su base la discriminación de los reclamos según vía de ingreso. Según los datos, la mayoría de los reclamos entraron al sistema a través del libro de quejas, seguido por los canalizados a través de la atención telefónica del 147. Tomaremos este año como referencia de una tendencia que se mantuvo relativamente constante en el tiempo y que se corresponde con las registradas en años previos por la CNRT (Base de reclamos SUACI, 2012-2017).

Para darles tratamiento una vez que los reclamos ingresan al sistema SUACI, SBASE, procede a derivarlas para su resolución al operador. Éste tiene la obligación de atenderlas inmediatamente y de contestar a la misma SBASE en un plazo de 7 días hábilescontados a partir de la recepción del reclamo- informando las medidas tomadas o a tomar en caso de que no pudieran ser resueltas con celeridad, justificado dicha imposibilidad. SBASE acompañará su contacto con los usuarios de los informes elevados por la operadora respecto al tema en controversia y supervisará los contactos que esta última tuviera con los reclamantes (AOM, 2016).

Los mecanismos descriptos para el caso del subterráneo convivieron y solaparon y aún lo hacen, con las funciones del Ente Único Regulador de los Servicios de la Ciudad Autónoma de Buenos Aires. 
Este organismo con potestades sobre la regulación de los servicios fue creado por la Constitución de la Ciudad Autónoma de Buenos Aires en el año 1996 (art. 138), como ente autárquico con personería jurídica, independencia funcional y legitimación procesal. Su creación respondió a la incorporación en la Constitución local de garantías dadas a consumidores y usuarios (Art. 46).

La Ley 210/1999 que reglamentó su funcionamiento, estimó que el Ente tiene la responsabilidad de controlar, seguir y resguardar la calidad de los servicios públicos prestados por el Gobierno de la Ciudad, descentralizados o por terceros a los fines de: defender y proteger los derechos de los usuarios y consumidores, la competencia y el medio ambiente, velando por la observancia de las leyes que se dicten al respecto (art. 2). Para tal fin, está capacitado para ejercer funciones sancionatorias conforme a las reglas y principios establecidos en el art 22 de la Ley 210 de acuerdo con la gravedad y reiteración de la infracción. En la actualidad el ente controla los servicios de Mantenimiento y Conservación Vial por Peaje (Autopistas Urbanas); Playas de Estacionamiento por Concesión; Estacionamiento medido (Tickeadoras); Captación fotográfica de infracciones de tránsito (Fotomultas); Servicio de Autotransporte Público de Pasajeros (Colectivos); Servicio de Subterráneo y Premetro; Servicio Público de Taxis; Servicio Público de Transporte Escolar; Residuos Patogénicos y Peligrosos; Alumbrado Público (luminarias); Señalamiento luminoso (semáforos); Transmisión de TV por cable; Transmisión de datos; servicio de higiene urbana.

Según lo publicado en el "Manual del Usuario" del Ente (2017), este tiene la capacidad de intervenir sobre las 33 líneas del autotransporte de pasajeros de Jurisdicción Nacional que comienzan y terminan su recorrido al interior del perímetro de la Capital Federal. Puede hacerlo de acuerdo con el código de Tránsito y Transporte de la Ciudad Ley 2.148/2006. Con el pasaje del servicio de subterráneos y del premetro, el Ente es el encargado de controlarlo en todo lo atinente a las obligaciones del prestador que abarcan desde el acceso, pasando por el personal de servicio, estaciones y vagones (Manual del usuario Ente, 2017).

De acuerdo con los testimonios de los informantes clave, desde su creación hasta la actualidad, el Ente se caracterizó por su baja capacidad institucional para poder ejercer la función regulatoria en el área de trasporte. Primero al estar durante una cantidad significativa de años todos los servicios bajo la órbita de la CNRT. Segundo ya con los subterráneos bajo jurisdicción de la Ciudad, indican que su papel supletorio respondió a políticas de jerarquización del Ejecutivo local de otras instancias de canalización de disconformidades con los servicios (Entrevista académico especializado, 17 de diciembre de 2018).

En el caso del subterráneo de Buenos Aires, la creación del Sistema Único de Atención Ciudadana al que referimos con anterioridad, también avanzó sobre áreas de injerencia del Ente Único, al verse canalizados los reclamos por dicha vía, la oficialmente jerarquizada y publicitada. Según indican, el SUACI sólo canaliza la demanda y la deriva para su resolución a quien corresponde, pero no tiene capacidad sancionatoria, potestad que sí tiene el Ente: "Como el Gobierno ejerce una autoridad política operativa, genera direcciones por ejemplo el 147, o los diferentes teléfonos. La gente llama más ahí en vez de recurrir al ente regulador (...) Le compiten al ente" (Informante clave Ente Único, 29 de enero 2019).

Este corrimiento al que asisten los entes de control instala dos cuestiones problemáticas respecto a sus funciones y sus posibilidades de producción de información en la materia a la que se está atendiendo. 
Como señalan Acuña y Chudnovsky (2013), las reglas institucionales pueden ser formales (definidas por el derecho positivo o regulaciones escritas) o informales (consensos sobre cómo funciona o debería funcionar algo) y muchas veces, actúan superponiéndose. Como señalan los autores, suele asociarse el incumplimiento de reglas estables como sinónimo de debilidad institucional, sin embargo, no necesariamente la primera es indicador de la segunda. Por el contrario, los márgenes de autonomía relativa respecto de los parámetros establecidos en los diseños formales que se generan en el campo de la acción, pueden aportar favorablemente al desenvolvimiento de una determinada práctica desarrollada bajo estas condiciones que no necesariamente era la prevista pero que sin embargo, en el orden de los comportamientos, funciona.

Para el caso de la CNRT puede hipotetizarse que la reasignación de funciones por el cumplimiento efectivo de la normativa pasándola a instancia de segundo término, implicó para el ente regulador una disminución de sus capacidades estatales en materia de ejercicio de control sobre el comportamiento empresario en lo relativo al contacto con el usuario y sus reclamos. Éstas entendidas como las aptitudes administrativas que le permiten al Estado proseguir con sus objetivos (Castellani y Llanpart, 2012). En este caso del ente autárquico encargado del control y fiscalización de los servicios de trasporte.

Al dejar de recibir la CNRT los reclamos en primera instancia, se retrajo el volumen de quejas tratadas por el organismo, lo cual imposibilitó que este pueda disponer de una base de información de volumen significativo que le permita contrastar lo mensualmente enviado por las empresas. Es decir, sostenemos que bajo estas condiciones la CNRT perdió la posibilidad de recibir y dar tratamiento directo a los reclamos pasando a depender de lo informado por las operadoras. Consideramos que esta cuestión juega desfavorablemente a la construcción de estadísticas oficiales que cumplan con criterios sistematicidad y fidelidad para los servicios bajo su jurisdicción.

Igualmente, las características específicas que tiene el subterráneo de Buenos Aires instalan problemáticas disimiles a las del autotransporte y los trenes urbanos. Desde su creación hasta la actualidad las capacidades limitadas del ente regulador fueron una constante más que una variable. Correspondiendo el análisis de esta debilidad a otros interrogantes analíticos. Por lo pronto en lo que refiere a la producción de datos vinculados a los reclamos de usuarios de los servicios de transporte, fue la dislocación de los tipos de registros en el pasaje de uno a otro, lo que afectó las formas de relevamiento y construcción de la información. Los cambios en la codificación y las dificultades para la construcción de series son los elementos problemáticos emergentes (Base de reclamos CNRT, 2002-2011 y Base de reclamos SUACI, 2012-2017). Previo a adentrarse a ellos se indagará en el conocimiento y valoración que tiene quienes utilizan los servicios respecto de estas vías.

\section{Los canales de reclamo en la mirada de los usuarios}

Para avanzar sobre las representaciones que tienen los usuarios respecto de los canales institucionales de reclamo, se encuentra a disposición un acervo nutrido de datos respecto a esta dimensión en serie histórica para el caso de los ferrocarriles de superficie. Para los otros modos se dispone de un registro puntual que igualmente permite realizar una aproximación a lo que ocurre en relación con este eje en los otros modos. Como se verá las tendencias detectadas manifiestan un comportamiento modular al conjunto de los servicios públicos de transporte colectivo metropolitano.

Existe entre los usuarios de los servicios de transporte una distancia entre exponerse a situaciones que le generan disconformidad con la prestación y su materialización en un reclamo formal. En diversos relevamientos de la CNRT, los encuestados reconocieron 
mayoritariamente haber estado en distintas oportunidades expuestos a situaciones que les promovieron las ganas de efectuar una queja y -sin embargo- no haberlo hecho. Esta distancia era captada al interrogar a los pasajeros si alguna vez habían sentido el deseo de reclamar por las condiciones de prestación del servicio. Seguidamente, caso de recibir una respuesta afirmativa se les consultaba si habían realizado efectivamente la queja (Encuesta CNRT 2002-2009). Con base a las respuestas a las mencionadas preguntas pudo identificarse la existencia de una brecha entre deseo y práctica. De acuerdo con el testimonio de un usuario de trenes urbanos, la disconformidad se manifiesta, pero no se formaliza: "La gente se queja de todo, pero no por los canales, va despotricando en el tren pero después no va a los canales" (Usuaria 1, Línea Sarmiento, 2017).

Dos son los elementos que pueden reconocerse como aquellos que contribuyen a generar una distancia entre las ganas de quejarse y efectivamente hacerlo. El desconocimiento es uno de ellos. Al aproximarse a esta cuestión a partir de distintos relevamientos, una encuesta realizada por la CNRT en el año 2002, señalaba que alrededor del 65\% de los usuarios del servicio de trenes urbanos afirmada desconocer los medios de reclamo existentes. Lo mismo ocurrió al indagarse, por ejemplo, sobre la CNRT y sus funciones. Para los años con los que se cuenta con información disponible, la mayoría de los encuestados manifestaba no conocer al organismo, manteniéndose relativamente constante la proporción de usuarios que concordaban con esta afirmación (Encuesta CNRT 2002-2009).

A lo largo de los años, ésta continuó siendo una característica distintiva de los usuarios encuestados, de acuerdo con los relevamientos propios referidos. Con estos se complementó la exploración iniciada por la CNRT respecto de esta dimensión, el 63\% de quienes contestaron el cuestionario en el último relevamiento, manifestaba desconocer los medios para efectuar una queja (TCS, 2016). Al respecto en el marco de un grupo focal se ponía énfasis en las acciones de la empresa para dar a conocer los medios de reclamo: “La empresa hace propaganda de los canales de comunicación? Hay mucha gente que no los conoce" (Usuaria 2, Línea Sarmiento, 2017). Por otra parte, se señalaba el comportamiento de los usuarios al respecto: "También hay una desinformación de parte nuestra de saber cuáles son los medios de comunicación” (Usuario 1, Línea San Martín, 2017).

Más allá del conocimiento o no de una vía institucionalmente legitimada para reclamar, la percepción de eficacia de la forma entendida como la capacidad atribuida para resolver un problema, también es un elemento que incide en su utilización. Según los resultados arrojados por los relevamientos citados, al indagar sobre las percepciones de los usuarios acerca de las distintas formas institucionales formales de reclamo -como, por ejemplo- firmar el libro de quejas o dirigirse a la CNRT, tres cuartas partes de los encuestados (77\%), las consideraba nada o algo efectivas para dar respuesta a sus problemas. Para el año 2015, esta baja efectividad descendía al 56\%, igualmente manteniéndose como un atributo dado a los canales (TCS, 2010; 2015). De acuerdo con esta tendencia, según lo señalado en un grupo focal, un habitual reclamante decía que más allá de que suele quejarse, descree de su utilidad: "Lo que decíamos hoy, vos sentís que reclamas y que no llega a ningún lado" (Usuario 3, Línea Sarmiento, 2017). También se manifestaba una desconfianza respecto del tratamiento dado a las quejas de los usuarios: "Yo creo que también pasa un poco eso de que no sabemos bien cuál sería el canal más eficiente para recibir la queja. Porque vos decís "Yo sé que el libro de quejas, no creo que nadie vaya y lo lea” (Usuaria 4, Línea Sarmiento, 2017).

Estos elementos empíricos permiten tener un acercamiento a la percepción de los usuarios respecto a la efectividad que tienen los canales. En sus testimonios este descreimiento respecto a la funcionalidad de esta práctica se plasma también en señalar al reclamo como una actividad para la cual no se desea poner a disposición el tiempo que se requiere para hacerla: "Nunca hice el reclamo pero me imagino que lleva tiempo 
y si estoy viajado en tren no es que estoy de viaje haciendo una recorrida" (Usuario 2, Línea San Martín, 2017). Este mismo dato fue relevado por en distintas ocasiones. En el último relevamiento realizado, más de un tercio de los encuestados respondió no tener tiempo para hacer los reclamos (TCS, 2016). Aunque los resultados del material empírico a disposición no pueden generalizarse al conjunto de los pasajeros por las características del tipo de relevamiento implementado (debido a la factibilidad de realizar otros tipos de registros) permite igualmente tener un acercamiento a la dimensión explorada. Refuerza la pertinencia de los datos que al indagar a lo largo de los años sobre esta dimensión, los resultados tienden a reforzar las tendencias registradas.

En una aproximación exploratoria al caso de los ferrocarriles subterráneos y el autotransporte, también bajo la modalidad de encuesta, verificamos comportamientos similares a los registrados en los ferrocarriles de superficie. En ambos casos nuevamente el desconocimiento de los canales disponibles de reclamo es un dato que caracteriza a los encuestados. Al consultar a los usuarios de las líneas D y E, el $67 \%$ de quienes respondieron el cuestionario afirmó no conocer cuáles son las vías disponibles. No presentando variaciones según línea. En el caso del autotransporte este porcentaje se ubica en el 58\%. Aunque por las características del relevamiento no es comparable lo que ocurre entre los modos ni representativo del universo, para el caso del autotransporte, aunque el desconocimiento es un rasgo característico de la porción mayoritaria de los encuestados, con escasa diferencia porcentual lo hace en menor proporción. Un elemento que hipotetizamos influye en esta cuestión es cómo se informa sobre los mecanismos de reclamo. La cartelería al interior y exterior de las formaciones resulta fácilmente accesible al usuario. En el relevamiento realizado, una porción significativa de los encuestados al preguntárseles por cuáles era los canales de queja conocidos, respondían con expresiones tales como: "hay un teléfono en el cartel del colectivo" o "el 0800 del cartel del colectivo" (Relevamiento Hernandez, 2018).

También tanto en subterráneos como en el autotransporte, registramos una brecha entre las ganas de realizar un reclamo por problemas con el servicio y su efectivo ejercicio. En los ferrocarriles subterráneos, el 56\% de los encuestados manifestó haber sentido el deseo de quejarse mientras que sólo el 31\% efectivamente lo hizo. Entre estos el 67\% considera que su queja fue poco o nada efectiva para resolver su problema. Por su parte, entre quienes nunca lo hicieron las respuestas se dividen en tercios bajo el argumento de no sirve, no sabe cómo y no tiene tiempo. Encontramos en los encuestados, expresiones como: "No le dan importancia, no lo quieren mejorar" (Usuaria, Línea 1, Línea E, 2018) o "Tardas. Te suben el boleto y es un desastre y te quejas y te tienen media hora más y además tu horario de trabajo” (Usuario 2, Línea E, 2018).

En el caso del autotransporte la existencia de motivaciones para reclamar se distribuye entre los encuestados en porciones equivalentes (50\% y 50\%). Es decir, el deseo de reclamar tiende a disminuir. Igualmente, entre quienes manifiesta disconformidad y efectivamente se quejaron, la brecha se mantiene y sólo un $31 \%$ declaró haberlo hecho, atribuyéndole en un $75 \%$ una nula efectividad resolutoria. Por el lado de quienes sintieron el deseo de reclamar, pero no lo hicieron, la brecha se funda en que los mecanismos, no sirven, no tiene tiempo y no sabe cómo. Se recabaron testimonios tales como: "Cuando está lleno me dan ganas, pero en general, no tengo quejas" (Usuario 1, Línea 166, 2018) o "Se me pasó la bronca y me olvidé”" (Usuario 2, Línea 166, 2018).

Como se vio los datos tienden a converger para apuntalar como rasgo característico de los usuarios del transporte público colectivo metropolitano, una baja cultura de reclamo institucional formal, fundada principalmente en el componente del desconocimiento generalizado de los canales de reclamo. Por su lado entre quienes, si los conocen, existe un descreimiento significativo de que sea la vía efectiva a través de la cual puedan procesar su disconformidad y recibir una respuesta favorable. 
Cuadro 1. Tabla resumen conocimiento y valoración de los canales de reclamo. Fuente. Elaboración propia con base a datos por encuesta y entrevistas.

Canales institucionales formales de reclamo

$\begin{array}{ll}\text { Mecanismos más utilizados } & \begin{array}{l}\text { Poco conocidos } \\ \text { - Poco utilizados } \\ \text { - Poco efectivos } \\ \text { - Autotransporte: Línea } \\ \text { telefónica CNRT }\end{array} \\ \begin{array}{l}\text { Ausencia de cultura de reclamo } \\ \text { institucional formal entre los usuarios } \\ \text { de los servicios de transporte público } \\ \text { colectivo metropolitano }\end{array}\end{array}$

\section{Estrategias metodológicas para el procesamiento de reclamos}

Acorde a los datos brindados por la CNRT, SOFSE y el SUACI se dispone de información para los distintos modos relativa a la cantidad y tipos de reclamos realizados por usuarios desde que fuera decretada la emergencia de los servicios de transporte en el año 2002 hasta 2017, último registro al que se tuvo acceso. En este lapso fueron recibidos 259.748 quejas en el ámbito de los ferrocarriles de superficie (2002-2016), 126.902 en los ferrocarriles subterráneos (2002-2017), 125.590 para el autotransporte de pasajeros (2013-2017). Como se aprecia la duración de los períodos no es igual para cada modo. Se dará cuenta a continuación cuáles son los elementos que intervienen en la disponibilidad diferencial de la información.

Antes de ello una primera advertencia para dar tratamiento a los datos. Su lectura en absolutos permite tener un acercamiento a la cantidad de reclamos que se efectivizan para cada modo, no permiten así expresados generar una mirada comparativa. Esto sucede debido a que el volumen de demanda que tienen los servicios es muy disímil. Dicha condición lleva a hacer algunos señalamientos respecto a esta última dimensión y de qué manera estandarizar la información para hacerla comparable.

El autotransporte de pasajeros traslada aproximadamente 4,4 millones de usuarios por día, los ferrocarriles de superficie 1 millón y los ferrocarriles subterráneos $870 \mathrm{mil}$ (CNRT, 2018; DGEyC, 2018). Este dato está contabilizado en función de la cantidad de boletos pagos, pudiendo existir variaciones entre este y lo efectivamente trasladados. Al no disponer de los criterios implementados para la estimación de la cantidad de personas transportadas, tomar esta medida nos permite tener un criterio homogéneo para su estandarización.

Además, otras dificultades que el indicador presenta es que a diferencia del autotransporte, donde la concordancia entre pasajeros transportados y boletos pagos es más estrecha, en los modos guiados esto no sucede. Primero, por los altos niveles de evasión que registran principalmente los ferrocarriles de superficie. Además en los trenes urbanos desde octubre de 2013 en las líneas Mitre y Sarmiento, dejó de cobrarse boleto hasta que mejoraran las condiciones de prestación. Esta situación implicó que prácticamente por dos años fuera alterada la cantidad de boletos vendidos. Segundo, porque el sistema de combinaciones que tiene el ferrocarril subterráneo permite marcar el ingreso al servicio a través de una línea específica pero no detectar a quienes conectan tramos. De este modo quedan subregistradas las segundas etapas de viaje.

Con ambos conjuntos de datos la manera de aproximarse al procesamiento de esta información para el análisis de los reclamos de usuarios, requiere avanzar en su estandarización sobre una base común. Esta acción permite sortear las diferencias de 
volúmenes de pasajeros pagos que se mueven en cada subsistema y el sesgo que esto introduce a una lectura en cantidades. De acuerdo con lo señalado por un informante de la CNRT (2018) si se pone en relación el total de quejas registradas (sea cual fuere la vía de ingreso del reclamo) sobre el total de pasajeros y se lo multiplica por cien mil, se obtiene un índice de queja (Informante clave 1 CNRT, 2009). Éste permite establecer un criterio común para la comparación entre modos que tiene como denominador una medida constante.

De acuerdo con este indicador para los períodos señalados, el caudal de quejas recibidas por los ferrocarriles de superficie registró un promedio de 4.4 reclamos cada 100.000 boletos pagos. Según un informante clave de la CNRT durante el año 2017 el organismo no controló el envío de los reclamos por parte de las prestatarias ferroviarias que mensualmente están obligadas a presentar, aún, cuando no registren ninguna queja. Es por ello que se dispone de un registro parcial de la información que no permite prologar la serie a dicho año.

En el caso de los ferrocarriles subterráneos, este valor fue de 3 quejas cada 100.000. En los colectivos el valor aproximado al que puede llegarse según los datos disponibles fue de 2 quejas cada 100.000. Éstos son observables del poco uso que los usuarios hacen de estos mecanismos y que el dato que proviene de estas vías resulta un insumo en términos cuantitativos prácticamente marginal.

Existen otras particularidades para el procesamiento de esta información para el caso del autotransporte de pasajeros y los ferrocarriles subterráneos.

Para el primero el índice de queja es un valor estimado. El análisis de los reclamos vinculados a este modo presenta una serie de dificultades para realizar una operación homologable a la efectuada con los reclamos de los guiados. En primer lugar, se carece de la serie completa, al menos para el período de años sobre los que se indicó se está trabajando. Se disponen únicamente de aquellos recibidos por el ente de control entre los años 2013 y 2017.

Distintos son los argumentos que circulan respecto a la falta de su disponibilidad. Sea porque se indica que la obligatoriedad del organismo regulador es la de guardar expedientes por cinco años, entonces no se dispone de información previa a 2013. Sea porque en torno a ellos circulan versiones que sostienen una mala praxis respecto a su preservación y que por ende no se dispone de la información (Informantes clave 4 CNRT, 2018). Sea cual fuera la razón, su inexistencia es indicador nuevamente de las distancias que podemos apreciar entre lo institucionalizado y los comportamientos (Acuña y Chudnovsky, 2013); las incongruencias que en este espectro se abren al tratamiento dado a la información y su preservación y la magra ponderación dada a este tipo de indicador y a las posibilidades de su incidencia que se dan para el caso del autotransporte.

Otra dificultad se suma a su procesamiento. Se dispone solamente de los reclamos ingresados a través de la CNRT. No se tiene registro sistemático de los viabilizados por el 0800- de las empresas de autotransporte. Para este modo a diferencia de lo que ocurre con los guiados, según indican quienes se dedican a su procesamiento, el mayor volumen de quejas ingresa a través del ente de control. Sin embargo, no disponer de los registros recabados por las prestatarias, hace que el cálculo del índice de quejas resulte, aunque aproximado, subestimado.

La medición que corresponde al servicio de subterráneos presenta una interrupción en su registro para el año 2012. Esto se debe al cambio de jurisdicción y al nuevo sistema de reclamos que queda integrado al Sistema de Atención Ciudadana de la Ciudad de Buenos Aires. A partir de analizar el derrotero de este indicador en otro trabajo de 
propia autoría (Hernández, 2019) es posible sostener que las series confeccionadas por la CNRT entre 2002-2011 y lo registrado por el SUACI desde el 2013 en adelante, pueden compatibilizarse para el seguimiento de la evolución del índice de quejas. La tendencia tiende a recuperarse para el año 2014.

Transitado el análisis de la cantidad de reclamos, sus debilidades y la construcción de un mecanismo que permita sistematizar su procesamiento para darle niveles de comparabilidad entre modos, existe otro componente vinculado a los reclamos que es el motivo de la queja.

Para todos los casos la herramienta con la que cuentan los operadores que reciben los reclamos para categorizarlos es un libro de códigos. Para los servicios que estuvieron y están bajo jurisdicción nacional, existen distintos tipos de organización y clasificación de los motivos de reclamo. Luego de su traspaso, los ferrocarriles subterráneos fueron incorporados a otra lógica de tratamiento de la información.

Según fue indicado para el caso del autotransporte, la cantidad de reclamos mayoritaria ingresaba vía el ente regulador y su forma de clasificación respondía a los criterios dados por la institución. Siguiendo la codificación brindada por la CNRT y el agrupamiento respectivo de códigos que establece la Resolución 979/98.

Las quejas que pueden viabilizarse son aquellas relativas a los servicios de las líneas 1 a la 199 de jurisdicción nacional, vinculadas a: servicio (ej. desvío de recorrido o falta de frecuencia), vehículos (ej. deficiencia mecánica y/o de carrocería o falta de higiene), tarifas (ej. violación del régimen tarifario o descuento para pases especiales), conductor (ej. conducción a excesiva velocidad o imprudente) o empresa (ej. prestar servicios no habilitados. Ordenados bajo estas categorías existen 39 códigos ya estandarizados -entre los que se encuentran los utilizados para ejemplificar- a los que pueden estar asociados los reclamos. Un tercio de los códigos que identifican a los distintos tipos de quejas efectivamente realizadas, refieren a los comportamientos del conductor.

El principal problema que se registra es la falta de información para la construcción de series que permitan hacer un seguimiento en el tiempo. Por dicha razón si quisiera analizarse los motivos de reclamo, resulta más productivo que seguir la evolución de las principales baterías y razones destacadas de queja, dar cuenta de la composición global que éstos tienen.

Para el caso de los ferrocarriles de superficie, al menos durante una porción significativa de años, fueron dos los esquemas utilizados para la clasificación de los reclamos. La CNRT disponía de su propia codificación de reclamos. Esta consistía básicamente en un listado de posibles tipos de motivos por los cuales podía ser realizada una queja. Estaban agrupadas en baterías según el tema general al que refiriesen. La base de datos utilizada contaba con 8 grandes dimensiones en las que se agrupaban 34 códigos de reclamos. Estas son: comportamiento de los agentes; ambiente; estaciones; información; material rodante; servicio; seguridad y tarifa. Bajo esta gran clasificación eran recibidas directamente las quejas por el Ente (PDTS, 2016-2019).

Por su parte la base de datos que contiene los reclamos que realizaban los usuarios directamente vía las operadoras ferroviarias, muestra que existía una marcada diferencia para clasificar un mismo tipo de información. Éstas contaban con 15 baterías que agrupaban a 114 códigos de reclamo, tales como: accesibilidad; ambiente; comportamiento de los agentes; confort; explotaciones colaterales; evasión; explotación; información al pasajero; limpieza; oferta de servicio; regulación-tarificación; seguridad; venta de boletos; anuladas y diversas. La heterogeneidad de opciones disponibles contribuía a la dispersión de la información y al debilitamiento de los registros (PDTS, 2016-2019). 
Al tomar por separado ambos criterios de clasificación hacia su interior, las baterías no necesariamente cumplen con los principios metodológicos básicos relativos al carácter excluyente y exhaustivo que estas deberían tener, para evitar solapamientos o confusiones sobre dónde ubicar los distintos tipos de reclamo. En un grupo focal realizado con trabajadores dedicados a recibir las quejas en los ferrocarriles, señalaban dicha dificultad: "Me parece que el listado de código induce a errores porque permite que una queja sea codificada de maneras distintas" (Operador CAP 4, PDTS 2016-2019).

$\mathrm{Al}$ poner en correspondencia ambos registros se aprecia que existen baterías que utilizan los mismos nombres, pero su composición es disímil. Esta condición dificulta las posibilidades de realizar un análisis integrado de la información recibida por las distintas vías puesto que un mismo código puede corresponder a baterías diferentes o puede estar presente en un registro y no existir en el otro. A la vez, la cantidad de códigos de reclamo provistos a los operadores para clasificar las quejas presenta un alto porcentaje de ítems marginales que no reflejan para los usuarios una problemática recurrente y que, por lo tanto, no tienen altos niveles de uso pero que colaboran a su dispersión (Hernández y Rebón, 2017).

En adición, la faz operativa de la que disponían los operadores para computar las quejas no permitía cargar reclamos realizados por más de un motivo, debiendo abrirse otro formulario para asentarla. En trabajo conjunto con los operadores y operadoras de los Centros de Atención al Pasajero se vio que esta dificultad operativa, fomentó la emergencia de distintos problemas. Uno de ellos fue clasificar las quejas bajo el rótulo de "Diversas". En esta categoría no sólo se agrupaban los reclamos marginales, sino que allí se cargaban las quejas que refirieran a una multiplicidad de motivos. Esta situación presentó dos dificultades: por un lado, la unidad de registro dejó de ser el contenido del reclamo y pasó a ser el usuario. Por otro, se perdió el contenido del reclamo, ya que los diferentes motivos no fueron desagregados. Otro de los mecanismos implementados ante esta situación fue la priorización de uno de los motivos por parte del operador según su percepción respecto de lo que los usuarios manifiestan con mayor intensidad o más reiteradas veces: "Depende de lo que connote lo que diga. Depende de cómo es el reclamo y el énfasis que se pone" (Operador CAP 6, 2016) (Hernández y Rebón, 2017).

Igualmente existen estrategias que hacen posible la homologación de las bases para el trabajo con los datos. Para poder realizarla es necesario hacer uso de la información a nivel de los componentes de las baterías. En su distribución puede apreciarse una concentración en aquellos vinculados a las condiciones de explotación de los servicios y los relativos al comportamiento del personal en sus distintas funciones. Ambos tipos de reclamo concentran más del 50\% de los casos, tendencia que se mantiene constante en los distintos procesamientos realizados (Hernandez, 2019). Por esta característica es posible re-trabajar la información centrándose en los ejes problemáticos más significativos, representativos de las denuncias hechas por los usuarios. De este modo es posible trasponerse a la dispersión que presenta la información por las características de la herramienta de recolección utilizada y los criterios heterogéneos dados a su tratamiento según la vía de ingreso al sistema de reclamos. Estas dificultades comenzaron a ser tratadas en el período reciente por la SOF.SE. Según pudimos reconocer en el trabajo de campo, la empresa avanzó en la revisión del libro de códigos, articulando con el ente de control para definir las formas de clasificación de los reclamos ingresados buscando la consolidación de los registros. También fue readecuada la interfaz brindada a los operadores para recibir las quejas, apuntado a disminuir las dificultades a la hora de recabar la información y abrir la posibilidad de discriminar aquellos englobados en categorías de tipo residual. La apertura de mayor cantidad de vías de reclamo hizo necesaria también la revisión del tratamiento a ellos dado. También se implementó una política de comunicación activa de las vías de reclamo en estaciones y formaciones. Al ser relativamente recientes las novedades incorporadas en la materia, queda a futuro 
la revisión de los límites y potencialidades que las innovaciones introducidas trajeron a la construcción de registros y las posibilidades de elaborar estadísticas oficiales.

En relación con los subterráneos de Buenos Aires el cambio en la codificación dada a los reclamos dificulta las posibilidades de aunar las series de datos. Si bien las tendencias en los principales motivos permiten construir una imagen de largo plazo, no es posible unificar la elaborada por la CNRT mientras tuvo el servicio bajo su gestión y que presentó las mismas características a las que referimos para los ferrocarriles de superficie que la aplicada bajo el sistema SUACI.

La principal diferencia está en que entre 2002 y 2011, el libro de códigos de reclamo del ente y los concesionarios presentó una amplia gama de categorías para clasificar a los motivos de las quejas. A partir de 2012 con el sistema SUACI éstas disminuyeron significativamente y pasaron a ofrecerse de manera cerrada a los usuarios. Estas refieren a 16 tipos de reclamo puntuales y desagregados. Este formato se aplica tanto para los recibidos por los operadores como los realizados personalmente vía libro de quejas por los usuarios en las boleterías de las estaciones.

A diferencia del registro en los ferrocarriles de superficie una clasificación más acotada colabora en evitar una dispersión de categorizaciones que pudieran estar asimiladas a una misma problemática. Por el contrario, la asignación limitada de tipos de reclamo que puede realizar los usuarios obstaculiza el registro de temas de preocupación que no son ofrecidos al reclamante como motivo de queja. Ejemplo de ello es el hacinamiento que no está presente en la codificación SUACI pero que un relevamiento propio pudo comprobar que es uno de los problemas centrales que los usuarios del servicio manifiestan tener (Relevamiento 2018).

En suma, durante una porción significativa del período bajo análisis el tratamiento de las quejas presentó tres tipos de dificultades: falta de información acentuada según tipo de servicio, diversidad de criterios de registro, desactualización y ambigüedad en los libros de códigos y trabas operativas existentes para el procesamiento de aquellos reclamos que refirieran a más de un motivo. Esta condición promovió la heterogeneidad de los registros dificultando su comparabilidad y compatibilidad para su correcto seguimiento en el largo plazo. 
Cuadro 2. Debilidades y estrategias para el análisis de las bases de datos de reclamo de pasajeros por modos de transporte. Fuente: Elaboración propia con base a datos por encuesta y entrevistas.

\begin{tabular}{|c|c|c|}
\hline \multicolumn{2}{|l|}{ Canales institucionales formales de reclamo } & \\
\hline Principales debilidades & Estrategias & \\
\hline $\begin{array}{l}\text { Autotransporte } \\
\text { - Carencia de información previa al año } 2013 . \\
\text { - Subregistro de reclamos por falta de casos ingresados } \\
\text { vía empresas. }\end{array}$ & $\begin{array}{l}\text { - Análisis de la } \\
\text { composición global de } \\
\text { los reclamos. }\end{array}$ & \\
\hline $\begin{array}{l}\text { Ferrocarriles de superficie } \\
\text { - Doble esquema de codificación con dificultades de } \\
\text { compatibilidad. } \\
\text { - Multiplicidad de criterios de clasificación y dispersión } \\
\text { de información. } \\
\text { - Falta de precisión metodológica que cumplan } \\
\text { requisitos de exhaustividad y exclusión de categorías. } \\
\text { - Problemas en la interfaz utilizada para la recepción } \\
\text { de reclamos que contribuye a la construcción de } \\
\text { categorías residuales. Ej. "Diversas". }\end{array}$ & $\begin{array}{l}\text { Homologación de } \\
\text { bases a nivel de sus } \\
\text { componentes. }\end{array}$ & 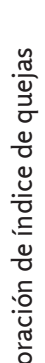 \\
\hline $\begin{array}{l}\text { Ferrocarriles subterráneos } \\
\text { - Incompatibilidad por cambio en el sistema de } \\
\text { reclamos con motivo del pasaje de jurisdicción para el } \\
\text { tratamiento de motivos de queja. } \\
\text { - Restricción de las categorías disponibles para la } \\
\text { efectuación de reclamos. }\end{array}$ & $\begin{array}{l}\text { - Reconstrucción de } \\
\text { serie a partir de la } \\
\text { tendencia del índice de } \\
\text { queja. }\end{array}$ & $\frac{\pi}{\square}$ \\
\hline
\end{tabular}

\section{Conclusión}

Disponer de información que permita conocer con precisión las percepciones y representaciones que tienen los usuarios de los servicios públicos respecto a los principales problemas que los afectan en su movilidad cotidiana es de relevancia por varias razones.

La posibilidad de realizar reclamos a través de los mecanismos dispuestos en los diseños institucionales es a priori la vía señalada para que los usuarios puedan encauzar sus disconformidades. La existencia de estos mecanismos de tramitación está fuertemente vinculada a la jerarquización que en tiempos recientes tomaron, al menos en sus directrices teóricas, la defensa de los derechos de los usuarios. Cobrando relevancia la regulación de las relaciones de prestación-consumo y la potestad estatal de velar por la defensa de los intereses de éstos últimos.

En este marco la posibilidad de los organismos que intervienen en dichas relaciones de hacerse de insumos que configuren observables de las condiciones en las que se brindan los servicios, en especial cuando estos están prestados por terceros, nutre los recursos de los que disponen potenciado su capacidad de acción e intervención.

De acuerdo con el recorrido hecho en estas páginas puede apreciarse una serie de debilidades articuladas en tornos a las posibilidades que tienen los órganos de control de los servicios de transporte de disponer de los reclamos de los usuarios como insumo de gestión.

Desde la óptica de quienes utilizan el servicio existe un desconocimiento generalizado de los canales de reclamo disponibles para realizar sus quejas vinculadas a las condiciones de prestación de los servicios. Se suma a esta cuestión que la porción minoritaria que conoce cuáles son las vías disponibles para ejercitar el derecho a reclamar, 
consideran que son poco efectivas para dar solución a sus problemas. Estas condiciones se traducen en una escasa cultura de reclamo formal y en la producción de un volumen de datos que resulta marginal en relación con el caudal de usuarios que se mueven por la red de transporte público colectivo metropolitano. En los últimos años las políticas orientadas a reforzar esta dimensión fueron erráticas y poco sistemáticas, no traduciéndose por el momento en un cambio en el comportamiento de los usuarios.

En lo atinente a la recepción y procesamientos de la información puede apreciarse que los canales de reclamo existentes son múltiples y diversos. En especial el desarrollo de las nuevas tecnologías, favorecieron su proliferación.

Igualmente se ve que existen dislocaciones entre las vías estipuladas y el tratamiento dado a la información. La heterogeneidad de canales de ingreso vinculados a instituciones y jurisdicciones diferentes colabora en la multiplicidad de criterios dados a su tratamiento. Mismas asincronías ocurren por los criterios establecidos para la organización y clasificación de la información. Esta condición debilita la posibilidad de construir datos consolidados.

Como telón de fondo será la orientación de las políticas de estado y lugar dado a la articulación del conjunto de relaciones que se despliegan en campo de los servicios públicos lo que coadyuvará a potenciar o limitar la disponibilidad de herramientas que colaboren en estrechar la brecha entre gestión y la dinámica cotidiana de la movilidad. Sostenemos que, frente al panorama descripto, las debilidades señaladas son uno de los observables que indican el estado de vulnerabilidad de los usuarios y sus derechos. La indefensión no es solo una cuestión de prestación. 


\section{Q Bibliografía}

" Acuerdo de Operación y Mantenimiento (2013). Acuerdo de operación del servicio público y mantenimiento de los bienes afectados al mismo de la red de subterráneos y premetro por medio del cual Subterraneo de Buenos Aires S.E (SBASE) otorga a Metrovías S.A dicha operación y mantenimiento en el marco de la emergencia establecida por Ley 4.472. Recuperado de: http:// Ippargentina.org.ar/subtedata/acuerdo-de-operacion-y-mantenimientosuscrito-por-sbase-y-metrovias-aom/

»Acuña, C. y Chudnovsky, M. (2013). Cómo entender las instituciones y su relación con la política: lo bueno, lo malo y lo feo de las instituciones y los institucionalismos. En Acuña, C. (comp.), ¿Cuánto importan las instituciones? Gobierno, Estado y actores en la política argentina (pp 18-67). Buenos Aires: Siglo XXI Editores.

" Auditoría General de la Nación (2009). Conformación empresarial del sector de Transporte Automotor de Pasajeros de Carácter Urbano y Suburbano de Jurisdicción Nacional. Informe especial. Buenos Aires: Auditoría General de la Nación.

»Botto, A. (2007). ¿Quién defienda a los consumidores? La regulación de los servicios públicos residenciales en Argentina y en Brasil después de las privatizaciones. Buenos Aires: Prometeo libros.

»Brennnan, P. (2008). El transporte urbano de pasajeros por ómnibus de Buenos Aires. Buenos Aires: Área de Pensamiento estratégico. Cámara Argentina de la Construcción.

» Bresser Pereira, L. C. (1998). La reforma del Estado de los años noventa. Lógica y mecanismos de control. Desarrollo Económico, 38, 517-550. Recuperado de: http://abcdonline.com.ar/tea/info/TEAo255.pdf

" Casaburi, G, Riggirozzi, M.P y Tuozzo, M.F (2000). Sociedad civil: Luces y sombras de una nueva relación. En D. Tussie, Luces y sombras de una nueva relación. Banco Interamericano de Desarrollo, el Banco Mundial y la sociedad civil. Buenos Aires: FLACSO

»Castellani, A. y Llanpart, F. (2012). Debates en torno a la calidad de la intervención estatal. Papeles de Trabajo, 9, 155-177.

»Castro, J.E. (2006). La lucha por la democratización de la gestión del agua y sus servicios. Legatus. Recuperado de: https://www.researchgate.net/profile/Jose_ Esteban_Castro/publication/311668106_La_lucha_por_la_democratizacion_ de_la_gestion_del_agua_y_sus_servicios/links/58534d2eo8aef7do30a51e17.pdf

»Constitución de la Ciudad Autónoma de Buenos Aires (1996). Art. 138. Ente Único Regulador de los Servicios Públicos. Ciudad Autónoma de Buenos Aires. Recuperado de: https://www.buenosaires.gob.ar/areas/leg_tecnica/sin/ normapopo9.php?id=26766\&qu $=c$

»Constitución de la Nación Argentina (1994). Art 42. Capítulo Segundo. Nuevos Derechos y Garantías. Recuperado de: http://servicios.infoleg.gob.ar/ infolegInternet/anexos/o-4999/804/norma.htm

»Decreto 104/1993. Comisión Nacional de Transporte Automotor. Creación. Poder Ejecutivo Nacional. Argentina. Recuperado de: http://servicios.infoleg. gob.ar/infolegInternet/verNorma.do?id=11668 
»Decreto 1.836/1993. Comisión Nacional de Transporte Ferroviario. Creación. Poder Ejecutivo Nacional. Argentina: Recuperado de: http://servicios.infoleg. gob.ar/infolegInternet/verNorma.do?id=16460

"Decreto 2.044/1993. Estructura Organizativa Comisión Nacional de Regulación del Transporte. Secretaría de Transporte del Ministerio de Economía y Obras y Servicios Públicos. Argentina. Recuperado de: http://servicios.infoleg.gob.ar/ infolegInternet/anexos/20000-24999/23436/norma.htm

»Decreto 656/1994. Autotransporte público de pasajeros. Permiso de explotación. Marco normativo. Poder Ejecutivo Nacional. Argentina. Recuperado de: http:// servicios.infoleg.gob.ar/infolegInternet/verNorma.do?id=16109

"Decreto 660/1996. Administración Nacional. Reforma del estado. Modificación de actual estructura. Poder Ejecutivo Nacional. Argentina. Recuperado de: http://servicios.infoleg.gob.ar/infolegInternet/verNorma.do?id=37574

»Ente Único Regulador de los Servicios Públicos (2017). Manual del Usuario. Ciudad Autónoma de Buenos Aires: Ente Único Regulador de los Servicios Públicos.

» García, A. (2008). Privatización, regulación y participación de la sociedad civil. La incidencia de las asociaciones de consumidores en la regulación de los servicios públicos. Buenos Aires: Centro de Investigación de la Regulación y del Derecho del Consumidor.

" González Moras, J.M. (2004). El concepto de servicio público. Revista Argentina del Régimen de la Administración Pública, 309, 185-210.

»González Moras, J.M. (2017). El servicio público como derecho social. Buenos Aires: Editorial de la Universidad de La Plata. Recuperado de: http://sedici. unlp.edu.ar/bitstream/handle/10915/62268/Documento_completo__.pdfPDFA.pdf? sequence $=1$

» Jirón, P., Águila, N., Imillán, W. (2019). Etnografía institucional como aproximación al habitar cotidiano. Revista temas sociológicos, 23, 215-245.

" Hernandez, C. (2019). Las vías del poder social. Límites y potencialidades a la capacidad asociativa de los usuarios/pasajeros del sistema metropolitano de transporte público colectivo (2002-2017). (Tesis para optar por el título de doctorado no publicada). Facultad de Ciencias Sociales, Universidad de Buenos Aires, Buenos Aires.

" Hernández, C. y Rebón, J. (2017). La calidad como reclamo. Los usuarios del sistema ferroviario de pasajeros del Área Metropolitana de Buenos Aires. Transporte Urbano e Interurbano en la Argentina. Aportes desde la Investigación. Buenos Aires: Eudeba.

"Ley 24.240/1993. Defensa del Consumidor. Régimen legal. Honorable Congreso de la Nación. Argentina: Recuperado de: http://servicios.infoleg.gob.ar/ infolegInternet/verNorma.do?id=638

»Ley 210/1999. Ente Único Regulador de los Servicios Públicos. Legislatura de la Ciudad Autónoma de Buenos Aires. Ciudad Autónoma de Buenos Aires. Recuperado de: http://www2.cedom.gov.ar/es/legislacion/normas/leyes/ ley210.html

» Ley 2.148/2006. Código de Tránsito y Transporte de la Ciudad Autónoma de Buenos Aires. Legislatura Porteña. Ciudad Autónoma de Buenos Aires. Recuperado de: http://www2.cedom.gob.ar/es/legislacion/normas/leyes/ ley2148.html 
»Ley 26.740/2012. Transporte Público de Pasajeros. Transferencia a la CABA de los servicios de transporte subterráneo y premetro. Honorable Congreso de la Nación Argentina. Recuperado de: http://servicios.infoleg.gob.ar/ infolegInternet/verNorma.do?id=195894

» López, A. y Felder, R. (1997). Nuevas relaciones entre el Estado y los usuarios de servicios públicos en la post privatización. Serie II Estado y sociedad. Documento № 30. Dirección Nacional de Estudios y Documentación. Dirección de Estudios e Investigación. Instituto Nacional de la Administración Pública (INAP).

"Olivieri, R. (abril de 1996). El usuario en la perspectiva de las políticas del transporte urbano. VIII Congreso Latinoamericano de Transporte público y urbano. CLATPU, Curitiba Brasil.

»Oszlak, O. (2004). Privatización y capacidad de regulación estatal: una aproximación teórico-metodológica. En: Bresser Pereira, L.C.; Cunill Grau, N.; Garnier,L.; Oszlak, O. y Przeworski, A., Política y gestión pública. Buenos Aires: Fondo de Cultura Económica y CLAD.

» Oszlak, O; Felder, R. y Forcinito, K. (2000). La capacidad regulatoria del Estado en Argentina. Área de Investigación de Privatización y Regulación de Servicios Públicos, Maestría en Administración Pública, Facultad de Ciencias Económicas, UBA.

»Oszlak, O y Felder, R. (1997). La capacidad de regulación estatal en la Argentina ¿quis custodiet custodes? En Isuani, A. y Filmus, D. (comps), La Argentina que viene. Análisis y propuestas para una sociedad en transición. Buenos Aires: Grupo Editorial Norma.

»Pérez, V. (junio 2018). Políticas públicas, representaciones y acción empresaria en el mercado de autotransporte público colectivo de pasajeros de la región metropolitana de Buenos Aires. XII Jornadas de Estudios Sociales de la Economía. Buenos Aires: CESE-IDAES

» Rabotnikof, N. (2001). La caracterización de la sociedad civil. Perspectiva de los bancos multilaterales de desarrollo. Nueva Sociedad, 171, 1-21.

»Real Academia Española (2019). Reclamar. Diccionario de la Lengua Española. Madrid: RAE.

»Resolución 405/1996. Transporte automotor de pasajeros y cargas. Reglamento del usuario. Aprobación. Comisión Nacional de Transporte Automotor. Argentina. Recuperado de: http://servicios.infoleg.gob.ar/infoleglnternet/ verNorma.do?id=37310

»Resolución 823/1998. Transporte Reclamos. Comisión Nacional de Regulación del Transporte. Argentina. Recuperado de: http://servicios.infoleg.gob.ar/ infolegInternet/verNorma.do?id=52016

»Resolución 979/1998. Transporte Automotor. Reglamento Pasajeros y Carga. Comisión Nacional de Regulación del Transporte. Recuperado de: http:// servicios.infoleg.gob.ar/infolegInternet/verNorma.do?id=37310

»Resolución 979/1998. Reglamento. Pasajeros y Carga. Comisión Nacional de Regulación del Transporte. Argentina. Recuperado de: http://servicios.infoleg. gob.ar/infolegInternet/verNorma.do?id=52355

»Subgerencia de Concesiones Metropolitanas (1999). Contrato de Concesión Grupo de servicios 3 y addendas. Buenos Aires: Comisión Nacional de Regulación del Transporte. 


\section{Candela Hernandez / candeher@gmail.com}

Doctora en Ciencias Sociales por la Universidad de Buenos Aires (UBA). Magister en Investigación en Ciencias Sociales (UBA). Licenciada en Sociología (UBA). Becaria postdoctoral del Consejo Nacional de Investigaciones Científicas y Técnicas (CONICET) con sede en el Instituto de Investigaciones Gino Germani (FSOC-UBA). 